\title{
Familial hyperaldosteronism
}

INSERM

\section{Source}

INSERM. (1999). Orphanet: an online rare disease and orphan drug data base. Familial hyperaldosteronism. ORPHA:235936

Familial hyperaldosteronism $(\mathrm{FH})$ is the heritable form of primary aldosteronism (PA) which comprises three identified subtypes to date: FH type I (FH-l; see this term) characterized by early-onset hypertension, glucocorticoid remediable adrenocorticotropic hormone (ACTH)-dependent hyperaldosteronism, variable hypokalemia, and overproduction of 18-oxocortisol and 18-hydroxycortisol; FH type II (FH-II; see this term) characterized by hypertension of varying severity and hyperaldosteronism not suppressible by dexamethasone; and FH type III (FH-III; see this term) characterized by profound hypokalemia, early-onset severe hypertension, non glucocorticoid-remediable hyperaldosteronism, and overproduction of 18-oxocortisol and 18-hydroxycortisol. 